\title{
Preface: some musings on fieldwork in a business context
}

\section{Malcolm Chapman}

I argued some time ago that there were two main obstacles to anyone wishing to carry out fieldwork in live and active business settings. These were access and disclosure.

The British, European, and North American anthropological fieldwork traditions all have a strong 'colonial' feel to them. The works of the founding fathers - Malinowski, Boas, Evans-Pritchard, Lévi-Strauss - all came from interactions between a 'Western, developed' perspective, and a 'primitive society'. There was a very obvious power imbalance, and a lack of interest, at the time, in the conditions and effects of this power imbalance. 'Access' to the primitive society was provided by the conditions of the social encounter; nobody really thought to ask whether the social anthropologist should knock before opening the door. In many modern business contexts, this is no longer so. The social anthropologist wishing to do fieldwork in a company can no longer arrive in the boardroom, pitch a tent, and expect to be welcomed or tolerated. Time is money, and the fieldworking anthropologist is, at best, a potentially expensive distraction. So, access is a problem. Access needs to be carefully negotiated, and even when granted can often be partially rescinded or compromised.

Disclosure is another issue that, in the early days, was not a problem, but which now can assume disabling proportions. In the 1920s and 1930s, social anthropologists had no qualms at all in publishing detailed documents about the personal, political, economic, and sexual lives of those that they studied. They had no qualms, either, about publishing photographs of these people. Many such black-and-white photographs were published, showing 'primitive' people partially or entirely 'naked' (it goes without saying, here and throughout, that every word or phrase that one uses to discuss such a situation merits its own 'deconstruction'). This had the interesting consequence that descendants of some of these people, coming perhaps to study the history of their countries or ethnicities in the libraries of the West, found photographs of their naked ancestors open to public view, in a society where nakedness was no longer an unmarked sociological feature. The nakedness of those in the photographs 
did not go unnoticed by the wider book-buying public. The best-selling monograph of the day was Malinowski's The Sexual Life of Savages (1929). Go figure. Something rather like a parameter collapse occurred, when the social anthropologist found, within a lifetime of active research and publishing, that the people who were being researched had got hold of what the anthropologist had written about their sexual lives, and were discussing it with interest, not unmixed with prurient detail. This happened, most notably as far as I know the matter, to the work and research that led to Wylie's Village in the Vaucluse. That was in 1974.

A social anthropologist writing up fieldwork research on a company cannot make the assumption, which came so easily to earlier generations, that the subject of the monograph (or article) will not be vitally interested in, and concerned about, anything that might be revealed. Business confidentiality can be very valuable, and breach of secrecy or confidence damaging in many ways, financially and otherwise. Even where access has been obtained, it may well be that the most interesting findings of a fieldwork episode cannot be disclosed.

I drew attention, at the same time (Chapman, 2001), to a further problem, which I called 'the black hole'. We are familiar with the (no doubt folk-scientific) notion of the black hole of astronomy, to which things enter but from which nothing returns. I used this metaphor as a way of summarizing an experientially powerful combination of the first two issues, access and disclosure, as they might present themselves to the fieldworking researcher. If a researcher has gained real and extensive access, and is in a position to make sensitive disclosures, then we could say that the researcher has achieved success in two rather different guises:

1. The researcher has conducted real fieldwork in the challenging environment of a modern business organization. Many people talk about it. Few actually do it.

2. The researcher has become, whether they like it or not, enmeshed in the transaction cost matrix of information that surrounds the firm, defining its boundaries and its relationships to competitor entities. It may be that the researcher has become so much part of the firm, that the researcher is worth much more to the firm than to the academy. And so the dense information gravity of the 'black hole' reveals itself: the knowledge stays inside the firm, and does not emerge to illuminate the seminar room, the lecture theatre, or the academic journal. The would-be academic becomes something else instead, probably more fun, and almost certainly better paid. 
Over the course of 30 years in business academia, I have been aware of a number of would-be or part-time doctoral students who have hovered uncertainly over this frontier, uncertain whether to commit to the black hole or to academia. And remember, we call it a black hole not because there is anything bad about it (as in the early Victorian cause célèbre 'the black hole of Calcutta'), but because knowledge goes in and does not come out again. The part-time doctoral student who hesitates seems to do so because there is an awareness that if he or she commits to the firm, then the PhD will never get written - the black hole closes around whatever knowledge they might gain. And if he or she commits to the $\mathrm{PhD}$, then the firm opportunities may close, or at least be compromised. The black hole has closed, leaving out what it perhaps does not need. Indeed, the issues at this point become definitional and tautologous.

There are many cases, of course, of students who have essentially been full-time academics, but who have gained reasonably good access to firms. And there are some cases, although notably fewer, of students remaining in post while writing a $\mathrm{PhD}$ about aspects of the company they work for. In many such cases, however, the resulting $\mathrm{PhD}$ is so hedged around with clauses concerning secrecy and anonymity (particularly concerning technological details that might identify either the sector or even the company), long-term embargoes, limitations or permissions relating to access, and legal contractual limitations, that the $\mathrm{PhD}$ is severely compromised as a contribution to knowledge. It is possibly extremely valuable to its author, and to the company that has sponsored it, and for whom the author works. It was worth doing, for that. Its limited availability, however, outside this audience, means that it can only contribute in the most general and probably vague terms to external debate. Insights that, with detailed corporate and technological context, are valuable, become, without these, the merest platitudes, the merest common knowledge.

Fieldwork is a method that comes from social anthropology. It has a background in the colonial period, and issues of access and disclosure need to be considered in the light of that, as already discussed. Management studies in their modern educational form were born, like many things, in the USA in the twentieth century. The first industrial nation, the UK, had technical and industrial colleges of various kinds, but none with the aim of investigating management, and making management better. The companies of the early waves of industrialism were nearly all family companies, and family companies, then as now, typically found their senior management from within. Knowledge came from these senior family members, and outside knowledge was always mistrusted, and often despised. Management studies, as conceived in the mid-twentieth century in the USA, came to sweep away this secrecy and tradition, by exposing management to the light and to the methods of 'science', as practised in the natural sciences: theory, hypothesis, data gathering, hypoth- 
esis testing, proof and disproof. The leading journals in business studies of all kinds, and in international business too, are all still of this kind. Those that are not, are conspicuous for not being, which tells the same tale.

'Fieldwork' has carved itself a precarious niche, within the intellectual ecology of positivist management science, as a 'preliminary' activity - something to be used in highly unfamiliar settings, where it might not be clear which questions to ask. This does not lead to the idea of fieldwork as a potentially better, more revealing, method than those associated with positivist science. It is, rather, a first step towards such methods. The research methods have implications for the analytical techniques, and for the kinds of questions that can be asked and answered, and I do not pursue these issues here.

I want to ask a question: why do practitioners of international business not read international business journals of the academic kind? Or perhaps, to put it more pointedly, why do executive lounges in international airports not all have subscriptions to Journal of International Business Studies (JIBS)? Why do the lounging executives not make off with the well-thumbed current issue, to steal a march on their competitors? Why is the subscription list of JIBS a list of business schools and not of multinational companies?

JIBS has been going for a little over 50 years. In some domains, 50 years might seem a long time. Look at physics, or chemistry, over the last 200 years, and any 50-year period contains periods of dramatic increase in the predictive power of science. For international business studies, not so much. International business studies came about as a result of the meeting of transaction cost economics, with the realities of differences between the existing nation states of the world. That is still what international business studies is about. The exciting ideas can, for extreme brevity, be condensed into the names of a few authors - Coase, Dunning, Buckley and Casson, Hofstede, Rugman. The debates and ideas are interesting, even vital, but predictive science they are not. When it comes to deciding which transaction cost is lower than the other, the answer still lies in the decision of the practitioner, not in the pages of JIBS.

If $J I B S$ could look at itself with genuine humility, this would not matter. But $J I B S$ only pretends humility; it wants greater success, and invites new ideas for achieving this, but it seems unable to consider stepping entirely outside the positivist paradigm; indeed, like a fish looking at water, it seems unaware that it even inhabits a paradigm.

Fieldwork, we argue, can allow a genuine escape from this. Fieldwork becomes, not a preliminary to a more refined positivism, but a method of objective scientific research in its own right. Objective - that's a word. The 'objective' that we mean is the 'objective' of those whom we research, the practitioners, the decision makers, the international business managers. In order to pursue this, our research is about trying to understand how these people see, understand, construct, manipulate, and envisage their world, with 
an eye to its past, present, and future. Fieldwork is our best window to understand 'objective reality', as understood in this way.

The fieldworker comes away from fieldwork with some understanding of what has been researched. Those who have been studied always have the better understanding (although the range of possible contextual issues intrudes here as an issue). The business researcher is thereby freed from the burden, which positivist research throws upon the shoulders, of pretending to have a better (because more truly 'objective' and 'scientific') knowledge than the practising manager. There are no 'managerial implications' at the end of such research, at least in the form of 'suggestions as to how you or people in a similar position might better do their jobs'. The humiliating and echoing emptiness of that particular section of your research paper can be dispensed with entirely.

There will, however, be some important lessons to be drawn from fieldwork research, which can be taken back to business academia. Positivist research would like to take back to business academia more theory, which contributes to the completion of the entire shiny building of scientific business studies. This is not what fieldwork research gives. Rather, what the fieldworker can take back to business studies is material for what should always be the primary role of the business school - the education (in the broadest sense) of managers. Managers that have been treated respectfully by research methods such as these, are also able to find a forum where their contribution to teaching and learning might be offered, and appreciated. It is the practising managers that are the epistemological arbiters of knowledge here, not the researchers.

Any business school teacher will know that an audience of even only moderately experienced students welcomes the input and insights of experienced practitioners, far more than those of positivist academics, whose only business qualification comes from the researching and writing of a positivist $\mathrm{PhD}$, and publication of resulting articles in business journals. The current relationship between business schools and researchers of the positivist kind is, in my view, a profoundly unhealthy one. It is based upon an unfounded assertion - that business researchers, through positivist methods, provide research, which has important 'managerial implications'. If this assertion were well-founded, international business practitioners would read JIBS. They do not. We need to build an entirely different ecology of knowledge, tying academia to business through the contribution that practising business practitioners can give to business education. A humble and thorough exertion of fieldwork research, conceived in these terms, can help to bring this about. 


\section{REFERENCES}

Chapman, M. (2001). Social anthropology and business studies: some considerations of method'. In D. Gellner \& E. Hirsch (Eds.), Inside organizations: anthropologists at work (pp. 19-33). Oxford: Berg.

Malinowski, B. (1929). The sexual life of savages in North-Western Melanesia. New York: Horace Liveright.

Wylie, L. W. (1974). Village in the Vaucluse. Cambridge, MA: Harvard University Press. 